\title{
sciendo
}

CIVIL AND ENVIRONMENTAL ENGINEERING REPORTS

E-ISSN 2450-8594

CEER 2020; 30 (2): 0015-0031

DOI: $10.2478 /$ ceer-2020-0017

Original Research Article

\section{EXPERIMENTAL INVESTIGATION INTO BANANA FIBRE REINFORCED LIGHTWEIGHT CONCRETE MASONRY PRISM SANDWICHED WITH GFRP SHEET}

\author{
Ramalingam VIJAYALAKSHMI $^{{ }^{*}}$, Srinivasan RAMANAGOPAL ${ }^{1}$ \\ ${ }^{1}$ Sri Sivasubramaniya Nadar College of Engineering, Tamilnadu India
}

\begin{abstract}
This paper presents the stress-strain behaviour of Natural Banana microfibre reinforced Lightweight Concrete (LWC) prisms under axial compression. The compressive strength of masonry is obtained by testing stack bonded prisms under compression normal to its bed joint. LWC blocks of cross-sectional dimensions $200 \mathrm{~mm}$ x $150 \mathrm{~mm}$ were used to construct the prism with an overall height of $630 \mathrm{~mm}$. Three series of specimens were cast; (a) prism without Banana fibre (control), (b) prism with Banana microfibres, (c) prism with Banana microfibres sandwiched with Glass Fibre Reinforced Polymer (GFRP) sheets. Natural Banana fibres were used as structural fibre reinforcement at different volume fractions (VF). The results indicate that the presence of fibres helps to improve the strength, stiffness, and ductility of LWC stack bonded prisms under compression. The test results also indicate that banana fibre reinforcement provides an improved crack bridging mechanism at both micro and macro levels. The GFRP sandwiched prism specimens exhibited excellent ductility and load-carrying capacity resulting from improved plastic deformation tolerance under compression and bonding between the LWC block and GFRP sheet.
\end{abstract}

Keywords: lightweight concrete, banana fibres, masonry prism, GFRP sandwich

\footnotetext{
${ }^{1 *}$ Corresponding author: Sri Sivasubramaniya Nadar College of Engineering, Rajiv Gandhi Salai, Kalavakkam, Chennai-603110, Tamilnadu, India; vijayalakshmir@ssn.edu.in
} 


\section{INTRODUCTION}

The lightweight concrete used in this study is produced by mixing cement, fly ash, foaming agent, and water in the required proportions in a ready-mix plant. The foam is pumped using specialized equipment that adds an air void at constant pressure. The density of the lightweight concrete is maintained after mixing and does not expand because the foaming agent does not undergo any gas-releasing chemical reaction. LEED (Leadership in Energy and Environmental Design), a green building certificate authority, has found lightweight foamed concrete production to be a sustainable technology which can help in the production of green building materials [1]. This is mainly because of low emissions of $\mathrm{CO}_{2}$ and the use of fly ash, which is a waste byproduct. LWC can, therefore, be used as a better alternative to clay bricks, the production of which uses approximately 50 tons of firewood for every 100,000 bricks [2]. When compared to clay brick, the production of lightweight foamed concrete has zero emission of pollution. Additionally, LWC blocks offer better strength, dead load reduction, good sound and thermal insulation, and a smaller number of mortar joints used for masonry construction, all of which helps to lower the cost [3]. Due to the lack of reinforcement, LWC has a lower capacity for energy dissipation and, therefore, the use of LWC has raised concerns in seismic regions. From the literature, it has been proved that fibre reinforced concrete has better energy absorption capacity and improved ductility [4]. A large percentage of buildings in India and around the world are Unreinforced Masonry Buildings (URM). These URMs are constructed using clay bricks and exhibit a brittle failure mode under seismic load, often leading to complete collapse and loss of life and property. Therefore, it is essential to develop sustainable, low cost, fibre reinforced blocks which are suitable for structural applications, particularly in a seismic environment.

\section{REVIEW OF LITERATURE}

The strength of cellular concrete in flexure is about $1 / 3$ to $1 / 5$ of the compressive strength [5]. Panesar [6] investigated the effects of synthetic and protein foaming agent on cellular concrete. The author also reported that the cellular concrete has strong potential to be used for lightweight structural applications due to its improved mechanical property, transportation property, and thermal resistance. The thermal conductivity of lightweight concrete depends on the density, moisture content, and ingredients of the material [7] and thermal and fire insulation properties are affected by the porous structure. Lightweight concrete with porous structure also has good acoustic insulation [8]. Addition of polypropylene fibre to concrete converts the cellular concrete from a brittle 
nature to ductile elastoplastic behaviour [9]. Natural fibre reinforced cement composites have been found to be attractive for low-cost building construction in developing countries [10] and natural fibres such as Roselle, sisal, coconut, sugar-cane bagasse, hemp, and jute are reported to yield improved compressive and tensile strength in cement-based composites [11-15]. The use of fibres to improve the characteristics of concrete can be traced back to ancient times. Natural fibres bring many benefits such as low cost due to their abundance, fewer health hazards, and flexibility. Merta and Tschegg [16] carried out an experimental investigation on the fracture energy of concrete composites reinforced with natural fibres and found that the addition of natural fibres enhanced the fracture energy of the composites. Joshi et al. [17] reported that, in most cases, natural fibre reinforced composites were environmentally superior to glass fibre reinforced composites.

\section{RESEARCH MOTIVATION \& OBJECTIVE OF THE STUDY}

From the study of the above literature, it can be inferred that the addition of fibres (both synthetic and natural) in concrete masonry can increase the structural integrity, leading to better durability and increased longevity. Researchers have in the past studied the load-deflection behaviour of fibre reinforced cellular concrete subjected to different modes of loading. Use of microfibres can arrest the cracking at a micro level and enhance the pre-cracking behaviour of masonry prisms, while macro fibres induce ductile behaviour in the post-peak region by arresting the structural cracking. Post-peak residual strength and ductile behaviour of LWC masonry can, therefore, be attained by the addition of fibres $[18,19]$. Review of previous literature indicates that there is very limited information on the mechanical properties of natural fibre reinforced LWC blocks of a density range between $800-900 \mathrm{Kg} / \mathrm{m} 3$. However, thorough knowledge about the behaviour and the failure modes of Banana Fibre Reinforced Lightweight Concrete (BFRLWC) masonry is necessary to formulate design guidelines. The objective of this study is (i) to understand the stress-strain behaviour of masonry prisms made of natural Banana Fibre Reinforced LWC blocks under compression and (ii) to study the pre-cracking behaviour and postpeak residual strength of GFRP sandwiched BFRLWC.

\section{EXPERIMENTAL INVESTIGATION}

The scope of the experimental investigation is to study the mechanical properties of lightweight concrete specimens. The experimental investigation is carried out in three series; series I is the testing of a control specimen, namely LWC block, LWC prism, and LWC cylinders. Mortar cylinders with cement and sand (1:6 by 
weight) were cast and tested under compression to obtain the stress-strain curve characteristics of the bed joint. Series II consists of compression testing of LWC prisms made of LWC block reinforced with Banana microfibres and plotting of the stress-strain curve to study the effectiveness of microfibre reinforcement in the energy dissipation capacity and failure modes. LWC blocks with varying fibre dosages were cast and tested to obtain stress-strain curves under compression. Thereafter, in series III, LWC prisms with fibre reinforced and GFRP sheets were pasted on the block to increase the tensile and shear resistance of the BFRLWC prism. The developed GFRP sandwiched BFRLWC masonry can be used as a load-bearing masonry construction in seismic zones, which would be largely subjected to compressive stresses and lateral forces. The objective of adding fibres was not to increase the compressive strength but more importantly to improve the post-peak behaviour under tension, flexure, compression, and their various combinations.

\subsection{Materials properties and specimen details}

Ordinary Portland Cement (53 grade), class F fly ash, foaming agent, and potable water were the four main ingredients used for the LWC mixture. Lime content in class $\mathrm{F}$ fly ash is typically less than $15 \%$. The foaming agent consisted of hydrolysed proteins and was diluted with water in a ratio of 1:40 (by volume), and then aerated to a density of $75 \mathrm{~kg} / \mathrm{m}^{3}$. The mix proportion of fly ash: cement: water: foam was $835: 280: 280: 1.4 \mathrm{~kg} / \mathrm{m}^{3}$. The water-binder ratio was kept constant at 0.4 , considering that fly-ash also acts as a binder. The addition of fibres in the mix by volume is not greater than $0.55 \%$ in the case of the highest dosage of fibre, i.e. $5 \mathrm{~kg} / \mathrm{m}^{3}$. The volume fraction of the fibre is determined by the ratio of the volume of fibre to the sum of volume of Fibres and Volume of Mix. The synthetic foaming agent is shown in Figure 1. Processed Banana Fibres (Figure 2.a) which are cut to the required length (Figure 2.b), used in this study, are shown in Figure 2. The physical properties of fibres are mentioned in Table 1. A batch of specimens with different volume fractions of micro-fibres such as $0.22 \%, 0.33 \%, 0.44 \%, 0.55 \%$ were cast. 


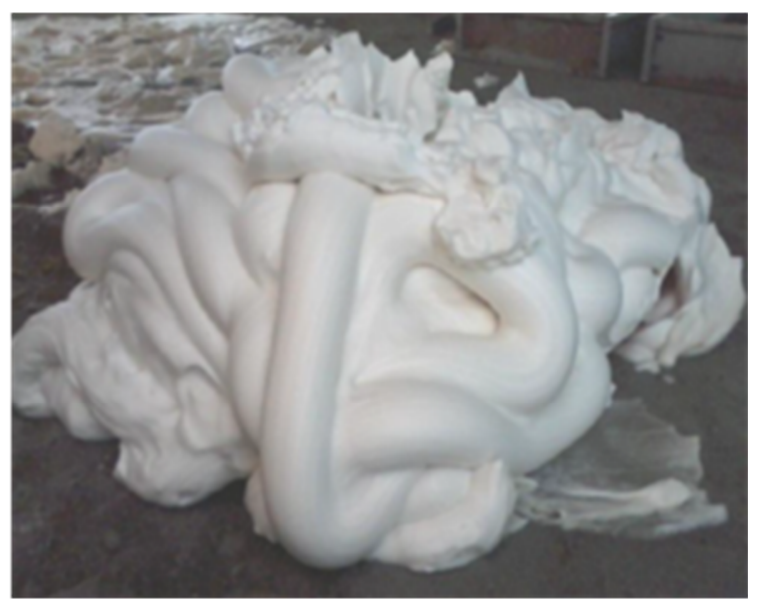

Fig. 1. Synthetic foaming Agent used in LWC mix
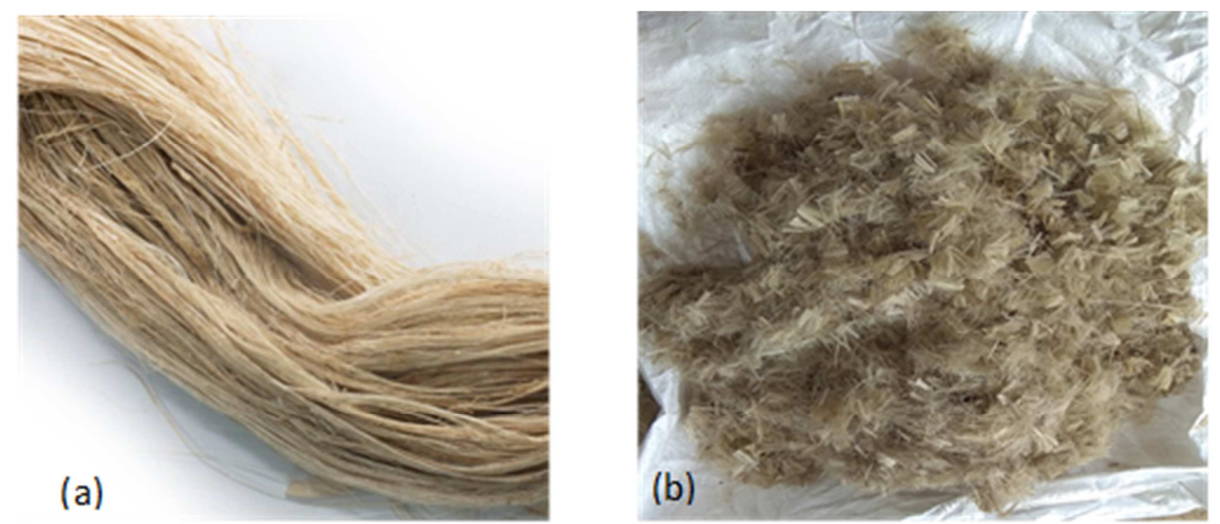

Fig. 2. Banana Microfibres used in LWC. a) Processed Banana fibre, b) Banana fibre cut into pieces $(6-8 \mathrm{~mm})$

The experimental program includes testing of LWC blocks without fibres, LWC blocks with banana fibre, mortar cylinders, LWC stack bonded prisms constructed with LWC blocks and mortar, and LWC stack bonded prisms sandwiched with GFRP sheet. Details of the specimen and fibre dosage are given in Table 2. The dimensions of the Stack bonded LWC prism sandwiched with GFRP sheet and bonded with cement mortar are shown schematically in Figure. 3 
Table 1. Physical and Mechanical properties of natural banana fibres

\begin{tabular}{|l|c|}
\hline Physical property & Range \\
\hline Raw material & Banana \\
\hline Type & monofilament \\
\hline Length & $6-8 \mathrm{~mm}$ \\
\hline Diameter & $0.08 \mathrm{~mm}$ \\
\hline Melting point & $120^{\circ} \mathrm{C}$ \\
\hline Acid and alkaline resistance & strong \\
\hline Density & $0.95 \mathrm{~g} / \mathrm{cm}^{3}$ \\
\hline Colour & brown \\
\hline Water absorption & $60 \%$ \\
\hline Specific Gravity & 1.48 \\
\hline Youngs modulus & $23 \mathrm{Gpa}$ \\
\hline Tensile Strength & $430 \mathrm{Mpa}$ \\
\hline
\end{tabular}

\subsection{Process of manufacture of LWC Mixture}

The dry raw materials, cement, and fly ash were first introduced into the mixer and mixed thoroughly enough to ensure even distribution of the contents. Potable-water was then added to the mixer until all the dry raw materials are converted to wet mix. The preformed foam was introduced at a rate of $35 \mathrm{gm} /$ $\mathrm{sec}$ for 40 seconds to the mixer. An additional 5 minutes of mixing was performed along with the fibres to get uniform consistency and to form a slurry of LWC. Thereafter, this slurry was poured into cuboidal moulds of $200 \mathrm{~mm} x$ $150 \mathrm{~mm} \times 600 \mathrm{~mm}$. After 24 hours, the specimens were remoulded, and curing was done as per IS-456 2000 (Plain and Reinforced Concrete - Code of Practice). The complete process of manufacture of LWC blocks is shown in the authors' previous publication [20]. The quantities of various materials were arrived at based on trial mixes. The density of LWC was not materially affected by the addition of fibres. A total void ratio of about 0.35 is used in order to achieve $900 \pm 50 \mathrm{~kg} / \mathrm{m}^{3}$ density. Water absorption tests carried out on LWC blocks showed that the water absorption was found to be 15 to $20 \%$, which is comparable to that of existing clay brick masonry. Prisms were cast using blocks of $200 \times 150 \times 600 \mathrm{~mm}$. Compression tests on LWC blocks were carried out in the displacement control mode, after curing for 28 days. Four LWC blocks were used for constructing each prism. GFRP sheets of size $600 \times 200$ were cut and pasted on the top of the block using epoxy resin. Cement mortar with cement of sand: weight ratio $1: 6$ and $10 \mathrm{~mm}$ thickness were used for joints. The constructed GFRP LWC prism sandwiched GFRP sheet is shown in Figure. 4. 
EXPERIMENTAL INVESTIGATION INTO BANANA FIBRE REINFORCED LLIGHTWEIGHT CONCRETE MASONRY PRISM SANDWICHED WITH GFRP SHEETT

Table 2. Details of the specimen to be tested and specimen ID

\begin{tabular}{|c|c|c|c|c|}
\hline Type of specimen & Series & Specimen ID & $\begin{array}{l}\text { Number of } \\
\text { specimens }\end{array}$ & $\begin{array}{c}\text { Fibre dosage } \\
(\%)\end{array}$ \\
\hline LWC Cylinder & \multirow{4}{*}{ I } & Control & 3 & 0 \\
\hline Mortar cylinder & & Mortar cylinder & 3 & 0 \\
\hline LWC Prism & & Control & 3 & 0 \\
\hline LWC Blocks & & Control & 3 & 0 \\
\hline \multirow{4}{*}{$\begin{array}{c}\text { Banana Fibre } \\
\text { Reinforced stack } \\
\text { bonded Prism }\end{array}$} & \multirow{4}{*}{ II } & Ba-mi-0.22 & 3 & 0.22 \\
\hline & & Ba-mi-0.33 & 3 & 0.33 \\
\hline & & Ba-mi-0.44 & 3 & 0.44 \\
\hline & & Ba-mi-0.55 & 3 & 0.55 \\
\hline \multirow{4}{*}{$\begin{array}{c}\text { Banana + GFRP } \\
\text { Sheet stack bonded } \\
\text { Prism }\end{array}$} & \multirow{4}{*}{ III } & Ba-GFRP-0.22 & 3 & 0.22 \\
\hline & & Ba-GFRP -0.33 & 3 & 0.33 \\
\hline & & Ba-GFRP -0.44 & 3 & 0.44 \\
\hline & & Ba-GFRP - 0.55 & 3 & 0.55 \\
\hline
\end{tabular}

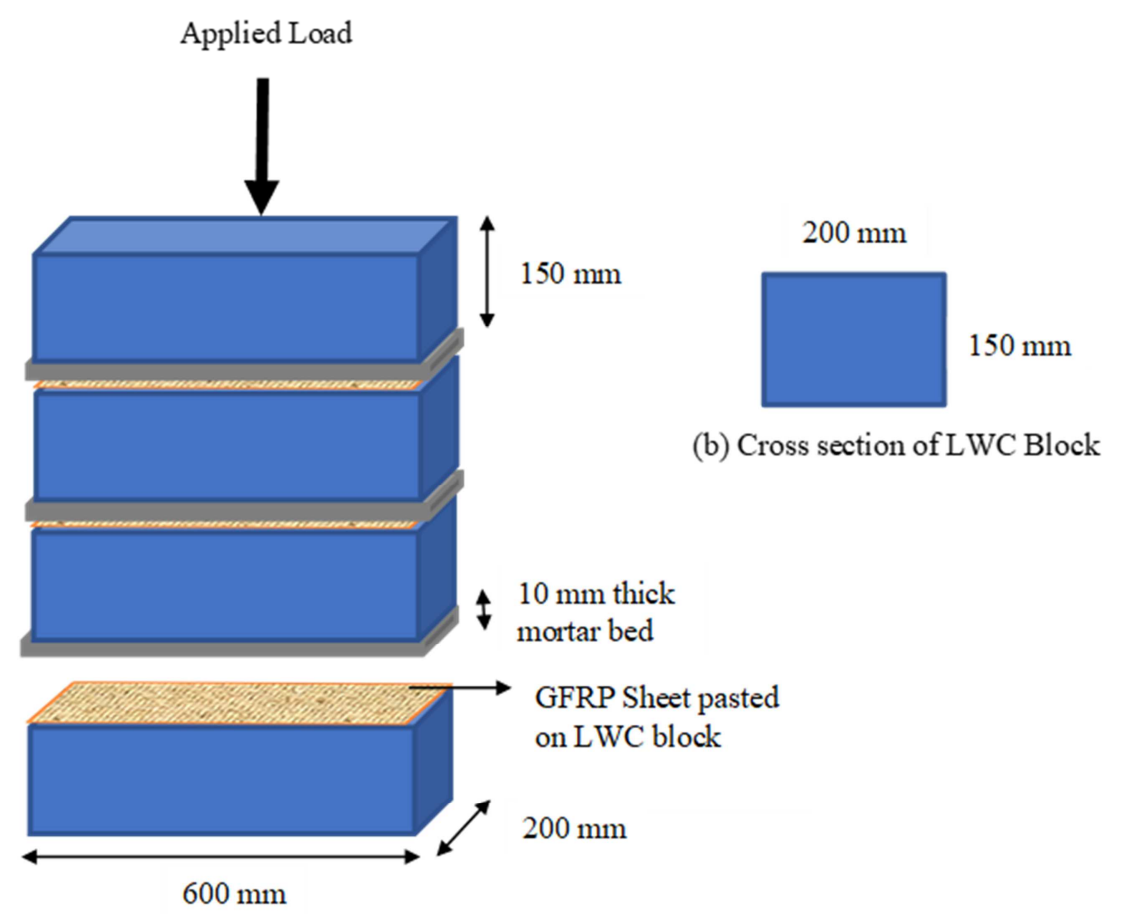

(a) Front view of Stack bonded Prism

Fig. 3. Arrangement of LWC stack bonded prism with GFRP Sheet for compression test 

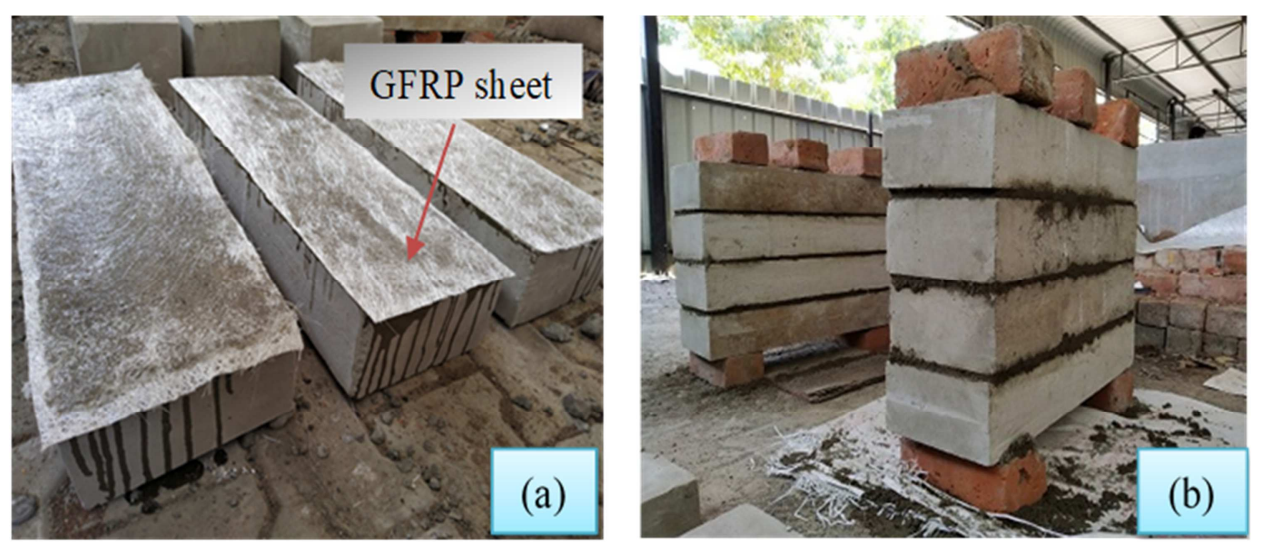

Fig. 4. LWC prism sandwiched with GFRP sheets. a) Pasting of GFRP sheet on the top of LWC block, b) stack bonded masonry prism

\subsection{Test Procedure}

The quality of a masonry structure is usually defined by its compressive strength. The American Society for Testing and Materials (ASTM) provides standardized test methods for compression testing of masonry specimens. Testing of masonry prisms is more economical than full-scale testing of masonry assemblages. The loading surfaces of the prisms were scraped and levelled to ensure a smooth contact area before testing. The load-displacement data were recorded through the Data Acquisition (DAQ) System. The prisms were tested using the servo-controlled compression testing machine. To provide a flat bearing surface and to distribute the load uniformly to the specimen, fibre boards were used on the top of the specimen. Testing of the prism specimen in compression was done in a servo-controlled compression testing machine by applying the load at a rate of $0.1 \mathrm{kN} / \mathrm{sec}$ up to $70 \%$ of the peak load. Thereafter, the loading was applied in displacement control mode at a rate of $0.001 \mathrm{~mm} / \mathrm{sec}$. The applied load was measured through a load cell and displacements were measured in the direction of loading using Linear Variable Displacement Transducers (LVDTs). The testing of the LWC block and LWC prism sandwiched with GFRP sheet is shown in Figure. 5 (a) \& (b), respectively. 

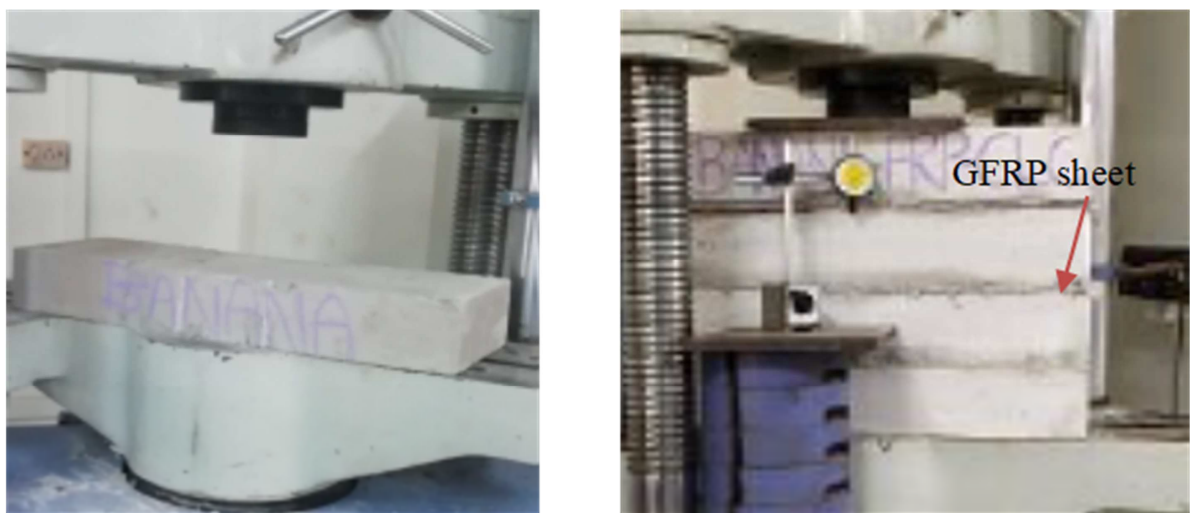

Fig. 5. Testing of LWC prism. a) Testing of LWC block, b) Testing of LWC Prism with GFRP sheet

\section{RESULTS AND DISCUSSION}

A total of 20 LWC prism specimens were cast. The test was conducted in three series; series I was the control with no microfibre reinforcement. Series II had banana micro reinforcement in the blocks with four different fibre dosages. Series III consisted of a BFRLWC prism sandwiched with GFRP sheet. A minimum of three specimens were tested for each series to ensure the consistency of results. The compressive strength results of the tested specimens are given in Table 3.

Table 3. Compressive strength of BFRLWC prism with GFRP

\begin{tabular}{|c|c|c|c|c|c|c|}
\hline \multirow[t]{2}{*}{ Type of specimen } & \multirow[t]{2}{*}{ Series } & \multirow[t]{2}{*}{ Specimen ID } & \multicolumn{3}{|c|}{$\begin{array}{c}\text { Peak Compressive } \\
\text { Strength (Mpa) }\end{array}$} & \multirow{2}{*}{$\begin{array}{c}\text { Mean } \\
\text { Strength } \\
\text { (Mpa) }\end{array}$} \\
\hline & & & 1 & 2 & 3 & \\
\hline LWC Cylinder & \multirow{4}{*}{ I } & Control & 4.5 & 4.9 & 4.7 & 4.7 \\
\hline Mortar cylinder & & Mortar cylinder & 7.3 & 7.2 & 6.8 & 7.1 \\
\hline LWC Prism & & Control & 3.5 & 3.8 & 4.2 & 3.8 \\
\hline LWC Blocks & & Control & 3.5 & 3.8 & 3.2 & 3.5 \\
\hline \multirow{4}{*}{$\begin{array}{c}\text { Banana Fibre } \\
\text { Reinforced stack } \\
\text { bonded Prism }\end{array}$} & \multirow{4}{*}{ II } & Ba-mi-0.22 & 3.6 & 3.8 & 4.0 & 3.8 \\
\hline & & Ba-mi-0.33 & 3.7 & 3.9 & 4.1 & 3.9 \\
\hline & & Ba-mi-0.44 & 4.4 & 4.2 & 3.7 & 4.1 \\
\hline & & Ba-mi-0.55 & 4.2 & 4.4 & 4.3 & 4.3 \\
\hline \multirow{4}{*}{$\begin{array}{c}\text { Banana }+ \text { GFRP } \\
\text { Sheet stack bonded } \\
\text { Prism }\end{array}$} & \multirow{4}{*}{ III } & Ba-GFRP-0.22 & 3.7 & 3.9 & 4.1 & 3.9 \\
\hline & & Ba-GFRP -0.33 & 4.3 & 4.2 & 3.8 & 4.1 \\
\hline & & Ba-GFRP -0.44 & 4.0 & 4.6 & 4.3 & 4.3 \\
\hline & & Ba-GFRP - 0.55 & 4.7 & 4.3 & 4.5 & 4.5 \\
\hline
\end{tabular}




\subsection{Compression behaviour of Control Specimens}

The compression behaviour of the LWC prism is briefly explained here for comparison with the compression behaviour of the control specimens. The stress-strain curve for the LWC prism compared to the LWC block and Mortar cylinder is shown in Figure 6. The LWC prism exhibited a linear stress-strain behaviour up to $30 \%$ of the peak load under axial compression. The elastic modulus of the Control LWC prism assemblies was less than that of both the mortar cylinder and LWC block, but greater than the elastic modulus of the LWC cylinder. The peak strength of the unreinforced LWC prism was $3.7 \mathrm{Mpa}$ which was closer to that of block strength $(3.5 \mathrm{Mpa})$. The compressive strength of the LWC cylinders was found to be in the range of $4.8 \mathrm{MPa}$. The elastic modulus of the mortar cylinder was $12200 \mathrm{Mpa}$, which is about three times greater than that of the block. However, the elastic modulus of the prism was $2100 \mathrm{MPa}$ which is less than $50 \%$ of the modulus of the LWC block (4100 $\mathrm{MPa}$ ). The failure in the prism is due to the effect of tri-axial compression in the blocks and bi-axial tension and uniaxial compression in the mortar (Figure 7).

The failure was initiated by tension cracking in the mortar followed by its propagation as cracks splitting into the LWC blocks, leading to the overall failure of the prism. After the peak load was attained, the Control LWC prism showed almost negligible resistance to the applied strain loading and the failure was quite sudden as the specimen collapsed. The failure mode exhibited by the control prism is predominantly a single explicit crack as shown in Figure 8. Stress concentrations in particular regions can be attributed to the inability of distributing the stress across the cross-section of the prism. The load transfer takes place largely around the crack region, leading to faster propagation of the crack. 


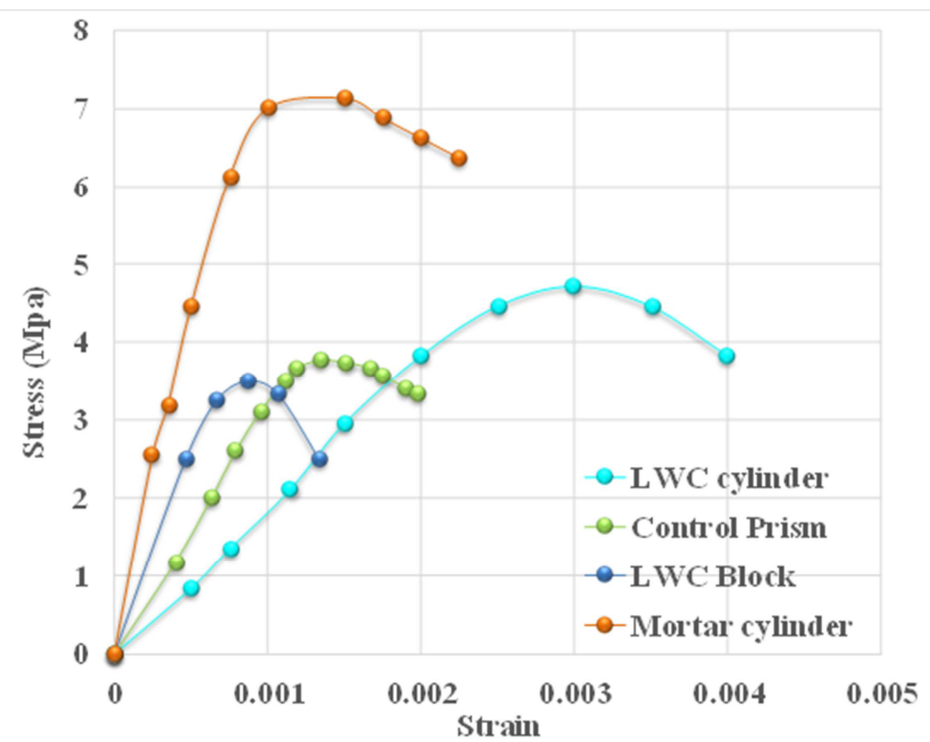

Fig. 6. Stress-Strain Curve of LWC prism and Control specimen
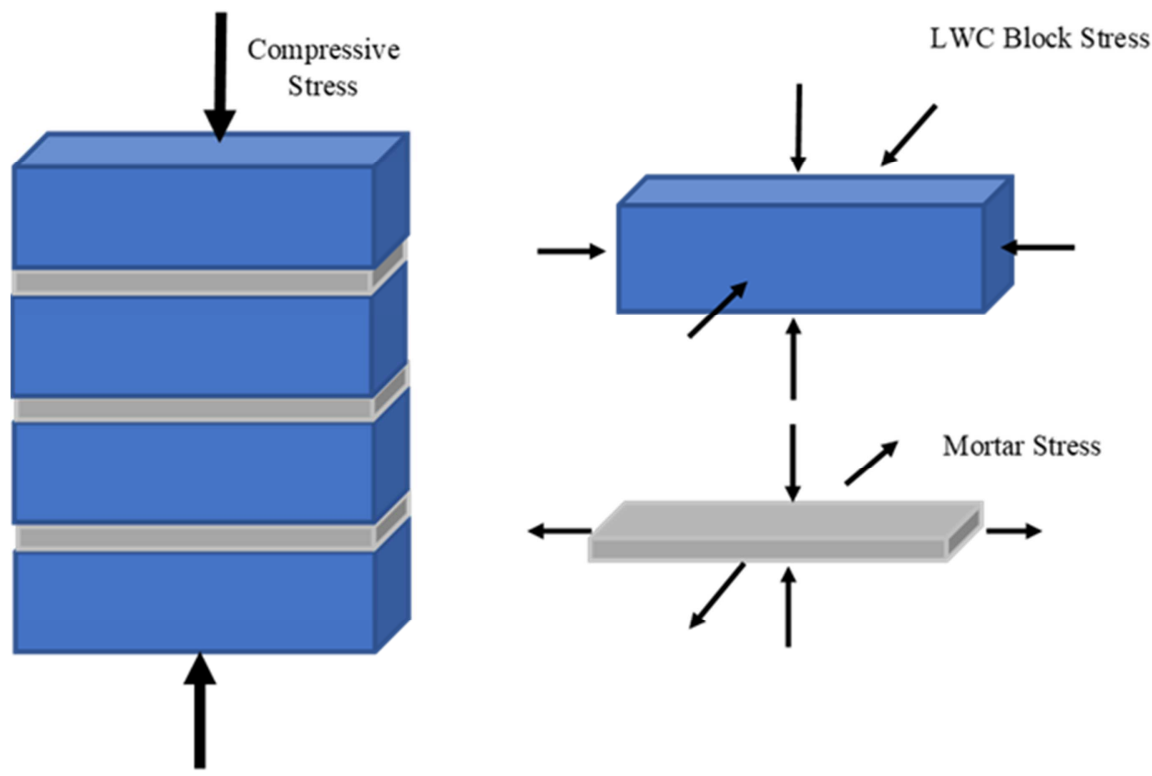

Fig. 7. State of stress developed in the components of the LWC prism 


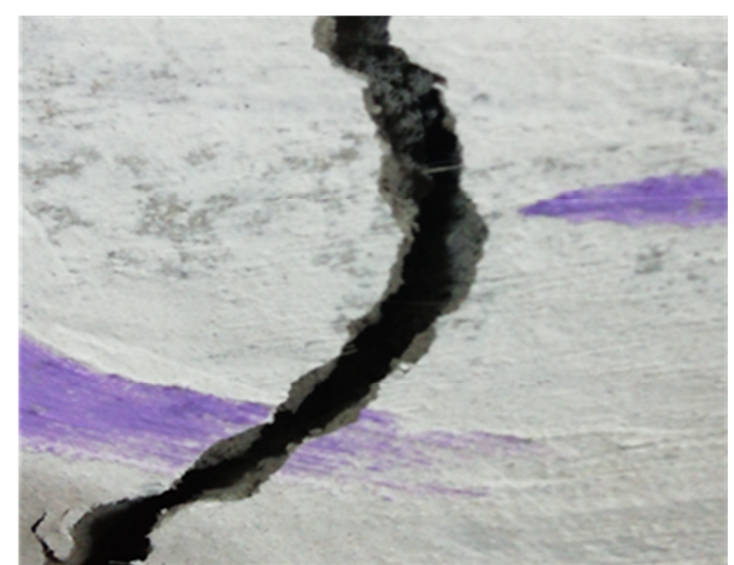

Fig. 8. Wide crack formation in the Control LWC prism

\subsection{Compression behaviour of BFRLWC prism}

From the stress-strain plot of the BFRLWC prism (figure 9), it was observed that there was a slight increase in the elastic modulus of fibre reinforced LWC prisms with the increase in fibre dosage. An increase in softening behaviour and less degradation in stiffness were observed in the post-peak region. The peak strength of BFRLWC prisms was higher than for the blocks and its elastic modulus was between that of the blocks and mortar. There was a slight increase in the peak compressive load of the fibre reinforced prisms compared to the control prisms. This increase in peak load is mainly due to the arresting of micro-cracks by the fibres, leading to an increase in peak compressive strength and better post-peak behaviour. Post-peak behaviour is improved in terms of residual load-carrying capacity and the compressive toughness index. A peak compressive strength of 3 to $5 \mathrm{MPa}$ was attained in this study. The presence of fibres in the LWC blocks led to better crack resistance, leading to improved post-peak behaviour. With the increase in load, a greater number of microcracks developed along the direction of loading. The propagation of cracks in the block is prevented by the fibres, which bridged the cracks (figure 10), leading to less degradation of strength with higher strains at failure. 


\section{LLIGHTWEIGHT CONCRETE MASONRY PRISM SANDWICHED WITH GFRP SHEETT}

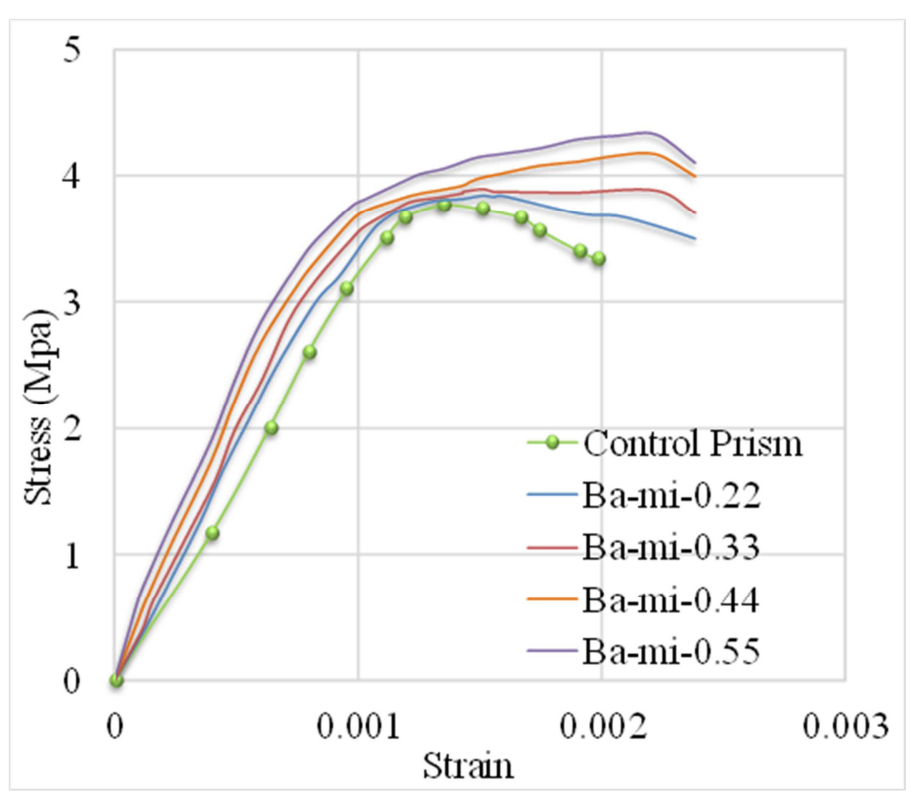

Fig. 9. Stress-Strain plot of BFRLWC Prism with different banana fibre dosage

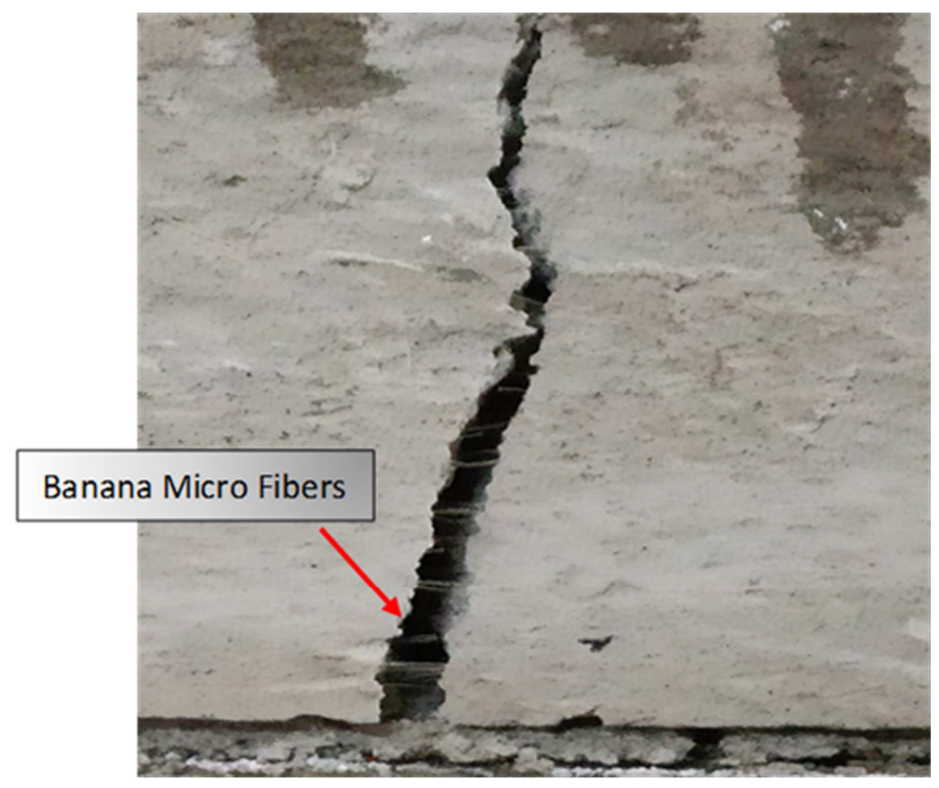

Fig. 10. Bridging of cracks by microfibres 


\subsection{Compression behaviour of BFRLWC prism sandwiched with GFRP layers}

The stress-strain plot of the BFRLWC prism sandwiched with GFRP sheet is shown in Figure 11. It was observed that the increase in the elastic modulus of the specimen was significant with the addition of GFRP sheet. The softening behaviour was found to be more pronounced in the post-peak region and less degradation in stiffness was observed. The peak strength of GFRP-BFRLWC prisms was higher than for the BFRLWC prism. There was a slight increase in the peak compressive load due to the addition of the GFRP layer. This increase in peak load is mainly due to the arresting of micro-cracks by the fibres and GFRP layers which led to the increase in peak compressive strength and better post-peak behaviour. Post-peak behaviour is improved in terms of residual load carrying capacity and compressive toughness index. Peak compressive strength of 4 to $5 \mathrm{MPa}$ was attained in this study. The failure was initiated by tension cracking in the mortar, which is further transmitted to the block. Stress concentration in a particular region and sudden failure of the specimen was prevented by the GFRP layers in the prism. Microfibres and GFRP layers bridge the crack and distribute the stress to the entire cross-section, preventing the formation of a major crack plane (Figure 12). Addition of GFRP layers can improve the ductile behaviour of LWC under shear, tensile, and compression loadings making it suitable for seismic applications. This improvement can be attributed to the arresting of micro-cracks in the specimen, whereas the unreinforced specimen is observed to have crack localization in the major crack plane.

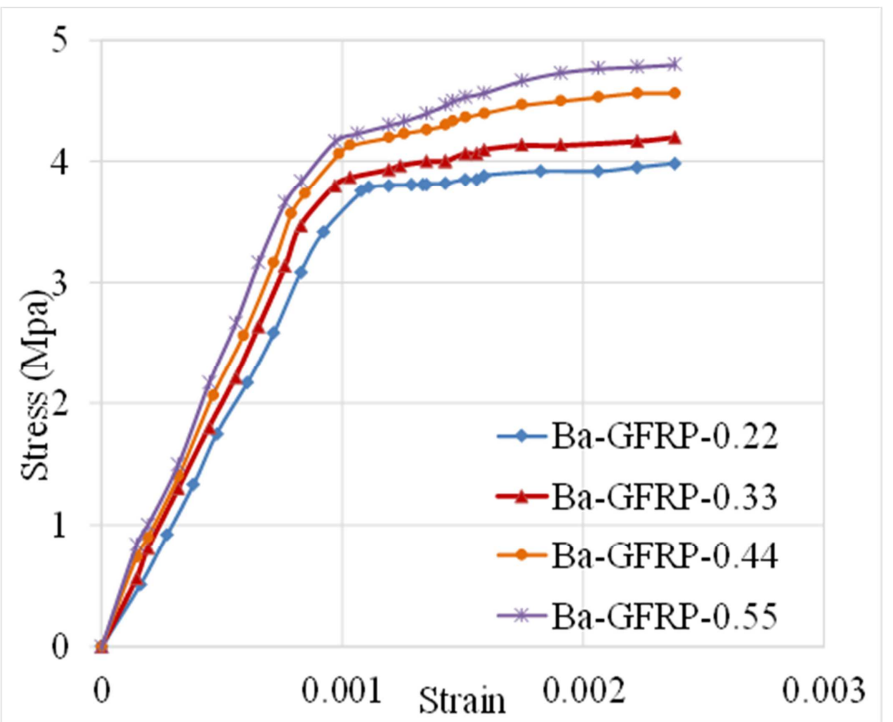

Fig. 11. Stress-Strain plot of BFRLWC sandwiched with GFRP sheets 


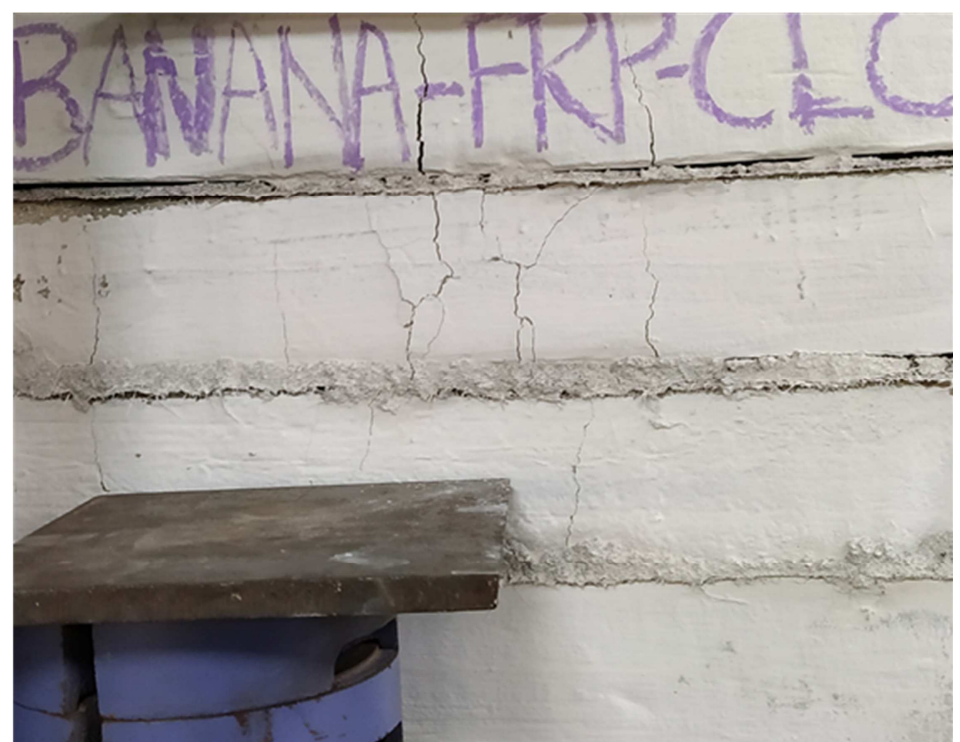

Fig. 12. Formation of micro-cracks in GFRP sandwiched LWC prism

The study into GFRP sandwiched BFRLWC indicates that the cost is only $25 \%$ higher than for normal LWC. Overall life-cycle analysis indicates that the beneficial effects of adding GFRP and fibres outweigh the additional cost incurred, especially for construction work carried out in seismic regions. Sudden failure and collapse of masonry constructions can be prevented by the addition of GFRP layers.

\section{CONCLUSION}

The effect of adding natural banana fibres and GFRP layers to LWC was studied by testing LWC stack-bonded prisms with various fibre dosages and different layers of GFRP sheets under compression. Based on the results obtained in this study, the following conclusions can be drawn:

- The compression behaviour of Control LWC prisms was similar to that of LWC block and LWC under axial compression. The failure in the prism was initiated by tension cracking in the mortar followed by its propagation as cracks splitting into the LWC blocks leading to the overall failure of the prism.

- With the addition of fibre, the compressive strength of LWC prisms increases progressively compared to that of the control prisms; the compressive strength increased up to $15 \%$ for $0.55 \%$ volume fraction of microfibre. 
- Failure of the Control LWC prisms was sudden due to stress concentration across the cross-section. The presence of banana fibres in the blocks led to better crack resistance and less degradation of strength and stiffness when compared to the control prisms.

- GFRP sandwiched BFRLWC stack-bonded prisms showed good composite behaviour under compression. The softening behaviour of the specimen was more pronounced in the post-peak region and the sudden failure of the specimen was prevented due to the presence of GFRP layers.

- The study on GFRP sandwiched BFRLWC indicates that the cost is only $25 \%$ higher than for the normal LWC. Overall life-cycle analysis indicates the beneficial effects of adding GFRP and fibres overweigh the additional cost incurred due to GFRP and fibre addition, particularly for masonry constructs in seismic regions.

\section{REFERENCES}

1. Satheesh babu, S 2010. Life cycle assessment of cellular lightweight concrete block - a green building material. J. Environ. Technol. Manage, 1554, 69-79.

2. Esmaily, $\mathrm{H}$ and Nuranian, H 2012. Non-autoclaved high-strength cellular concrete from alkali-activated slag. Constr. Build. Mater, 26, 200-206.

3. Zhang, B and Poon, CS 2015. Use of Furnace Bottom Ash for producing lightweight aggregate concrete with thermal insulation properties. Journal of Cleaner Production, 99, 94-100.

4. Yang, KH and Lee, KH 2015. Tests on high-performance aerated concrete with a lower density. Constr. Build. Mater, 74, 109-117.

5. Mobasher, B Li, CY 1996. Mechanical properties of hybrid cement-based composites. ACI Mater. J, 93, 284-299.

6. Kaushik, HB, Rai, DC and Jain, SK 2007. Stress-Strain Characteristics of Clay Brick Masonry under Uniaxial Compression. Journal of Materials in Civil Engineering, 19, 728-739.

7. Krishna, BSK 2012. Cellular light-weight concrete blocks as a replacement of burnt clay bricks. Int. J. Eng. Adv. Technol, 2, 2249-8959.

8. Zollo, RF and Hays, CD 1998. Engineering material properties of a fiberreinforced cellular concrete. ACI Materials Journal, 95, 631-635.

9. Kearsley, EP and Wainwright, PJ 2002. Ash content for optimum strength of foamed concrete. Cem. Concr. Res, 32, 241-246.

10. Panesar, DK 2013. Cellular concrete properties and the effect of synthetic and protein foaming agents. Cons. And Building Materials, 44, 575-84. 
11. Rasheed, MA and Prakash, SS, 2015. Mechanical behaviour of sustainable hybrid- synthetic fiber-reinforced cellular light-weight concrete for structural applications of masonry. Construction \& Building Materials, 98, 631-640.

12. Estabrag, AR, Rajbari, S and Javadi, AA 2017. Properties of a Clay Soil and Soil 8 Cement Reinforced with Polypropylene Fibers. ACI Materials Journal, 114, 195-206.

13. Rasheed, MA and Prakash, SS 2017. Behavior of Hybrid-Synthetic Fiber Reinforced Cellular Lightweight Concrete under Uni-axial Tension Experimental and Analytical 20 Studies. Construction and Building Materials.

14. Wee, TH, Babu DS, Tamilselvan, TLH 2006. Air-void systems of foamed concrete and its effect on mechanical properties. ACI Materials Journal, 103(1), 245-52.

15. Drysdale, RG and Hamid, AA 2008. Masonry Structures: Behavior and Design. The Masonry Society: Boulder, CO.

16. Gumaste, KS, Nanjunda Rao, KS and Venkatarama Reddy, KSJ 2007. Strength and elasticity of brick masonry prisms and wallettes under compression. Materials and Structures, 14, 241-253.

17. Joshi, SV, Drzal, LT, Mohanty, AK and Arora, S 2004. Are natural fiber composites environmentally superior to glass fiber reinforced composites. Composites Part A, 35(3), 371-376.

18. Rasheed, MA and Prakash, SS 2018. Behaviour of Hybrid-Synthetic Fiber Reinforced Cellular Lightweight Concrete under Uni-axial Tension Experimental and Analytical Studies. Construction and Building Materials, 162, 857-870.

19. Vijayalakshmi, R and Ramanagopal, S 2020. Compression behaviour of polypropylene fiber reinforced cellular light weight concrete masonry prism. Civil and Envi. Eng. Reports, 30 (1), 145-160.

Editor received the manuscript: 06.04.2020 